environment and provide skills for the future. Some participants suggested it would be helpful at the start of their post in Medicine for the Elderly.

All Doctors reported gaining confidence in challenging conversations and in particular DNACPR discussions.

Conclusion Foundation Doctors appreciate the opportunity to develop confidence in communication skills at a very early stage in their career. Embedding these skills early can help to improve life-long communication, patient care and reduce complaints.

\section{AUDIT ON THE IMPACT OF NEW GUIDANCE ON STRONG OPIOID PRESCRIBING FOR ADULT PALLIATIVE CARE PATIENTS IN A LARGE HOSPITAL TRUST}

Laura Deacon, Catriona Jackson, Sunita Hensch, Suzie Gillon. Leeds Teaching Hospitals NHS Trust

\subsection{6/bmjspcare-2018-ASPabstracts.55}

Background Following a series of clinical incidents it was recognised that guidance on the use of strong opioids for adult palliative care patients was needed to reduce errors and improve safe prescribing.

Extensive guidance was developed by the palliative care team and disseminated and publicised. This audit reviewed the impact of this guidance on opioid prescribing standards.

Methods Two wards with a large number of palliative care patients were identified, an oncology and a respiratory medicine ward. The ward 'Controlled Drug' registers were used to identify patients receiving strong opioids. Full case note and drug chart review was completed and each opioid prescription and corresponding notes were analysed.

Baseline results were obtained prior to the dissemination of guidance. The second round was completed eight months after the guidance had been published and publicised.

Results A total of 80 case notes and 140 opioid prescriptions were audited across the two rounds. The respiratory patients were older and had a wider range of pathologies but oncology patients were more likely to be on strong opioids on admission.

Compared to baseline, the second round demonstrated that more patients had their admission opioids appropriately titrated (87\% vs $64.5 \%)$.New opioid prescriptions also had more appropriate PRN dosing, review (57\% vs 53\%) and titration (76\% vs $71 \%)$.

The second round also demonstrated greater review of side effects (36\% vs 28\%) and associated supportive prescribing. Opioid toxicity was rare, occurring in only $6 \%$ of the patients audited with no recorded use of Naloxone.

Conclusions The audit was limited by it's size and availability of notes and drug charts, however, modest improvements in strong opioid prescribing were demonstrated. Dissemination of best practice in a large hospital Trust remains challenging and further audit should perhaps focus upon how best to embed new guidance within clinical practice.

\section{THE UNIVERSITY OF LIVERPOOL SCHOLAR PROGRAMME: DEVELOPING ACADEMIC CLINICIANS IN PALLIATIVE MEDICINE}

Amrita Rai, Sumandeep Bains, David Cassidy, Amara Nwosu, John E Ellershaw, Stephen Mason. University of Liverpool, Royal Liverpool University Hospital Trust

\subsection{6/bmjspcare-2018-ASPabstracts.56}

Background Medical students should understand the value of research and be able to 'formulate simple relevant research questions'. ... and design appropriate studies or experiments to address the questions (Outcomes for Graduates - Section 12b). However, it is often difficult for students to engage meaningfully with academic departments and clinical research. As a result, graduating Doctors are often under-prepared for postgraduate research and few engage in further academic training.

Aims The University of Liverpool Scholar Programme aims to accelerate the development of research skills by embedding medical students within an active clinical research department at early stage in their education.

Methods Selected students are offered the opportunity to apply to the Scholar Programme. An action plan is developed, and the academic partnership provides the opportunity for the Scholar to be mentored and supported in the development and completion of a student led research study.

Results The Scholar Programme began in 2014. Currently there are 57 Scholar students, producing several peer reviewed academic outputs. There are currently 6 Palliative Medicine Scholars, engaging in a range of projects from, a feasibility study on the use of the dignity question, to contributing to the development of a Core Outcome Set. Summary feedback indicates that, in addition to an enhanced understanding and working knowledge of research, the scholar programme provides substantial benefits to the personal and professional development of the student.

Conclusions The Scholar Programme is an effective way to provide academically focused medial undergraduates with the opportunity to understand the critical relevance and application of research evidence whilst developing transferable research and critical thinking skills. Although a new programme, providing students with this experience in Palliative Medicine may assist in developing future academic clinicians in the field.

\section{THE GLOBAL IMEP INITIATIVE: AN INTERNATIONAL PROGRAMME OF ASSESSMENT IN UNDERGRADUATE PALLIATIVE MEDICINE}

Stephen Mason, Amrita Rai, Patrick Colleran, Frank Elsner, Carlos Centeno, John Ellershaw. University of Liverpool, Royal Liverpool University Hospital Trust, Aachen University, Pamplona University

\subsection{6/bmjspcare-2018-ASPabstracts.57}

Background The number of patients with palliative needs is increasing globally. In response, the World Health Organisation has recommended that 'training and continuing education on 